ARTIGO

DOI: https://doi.org/10.22481/praxis.v14i30.4377

\title{
TEORIA CRÍTICA E ESCLARECIMENTO: MEDIAÇÃO PARA UMA EDUCAÇÃO ESCOLAR EMANCIPATÓRIA
}

\author{
CRITICAL THEORY AND CLARIFICATION: MEDIATION FOR AN EMANCIPATORY \\ SCHOOL EDUCATION
}

\section{TEORÍA CRÍTICA Y ESCLARECIMIENTO: MEDIACIÓN PARA UNA EDUCACIÓN ESCOLAR EMANCIPADORA}

\author{
Fátima Maria Nobre Lopes \\ Universidade Federal do Ceará - Brasil \\ Adauto Lopes Da Silva Filho \\ Universidade Federal do Ceará - Brasil
}

\begin{abstract}
Resumo: O processo de globalização do mundo contemporâneo afetou consideravelmente todos os setores da vida humana, inclusive a ciência, a tecnologia e a educação. Aqui se insere principalmente a educação escolar que, no caso do Brasil, atingiu certa universalização, embora a sua teleologia central esteja voltada mais para as demandas do mercado do que para a formação cultural e humana. A partir dessas considerações, este artigo objetiva dissertar sobre algumas concepções de Marcuse e de Adorno em torno da teoria crítica que poderão contribuir para o esclarecimento acerca da sociedade tecnológica e da barbárie que nela impera como condicionantes dos complexos sociais, dentre eles a educação escolar. Nesse sentido, a teoria crítica e, consequentemente, o esclarecimento poderão contribuir para a superação dessa dinâmica social instrumental tendo em vista uma educação escolar emancipatória.
\end{abstract}

Palavras-chave: Sociedade Tecnológica; Teoria Crítica; Esclarecimento; Educação Emancipatória.

\begin{abstract}
The process of globalization of the contemporary world reached considerably all the segments of the human life, including science, technology and education. In the case of Brazil and, especially, its school education, that process reached some universalization, although its central teleology focuses more on the market requests than on the cultural and human development. Based on these considerations, this article aims to discuss some conceptions of Marcuse and Adorno around the critical theory that can contribute to the clarification about the technological society and the barbarism that prevails in it as rulers of the social complexes, among them the school education. In this sense,
\end{abstract}


critical theory and, consequently, the clarification may contribute to overcoming this instrumental social dynamics in view of an emancipatory school education.

Keywords: Technological Society; Critical Theory; Clarification; Emancipatory Education

Resumen: El proceso de globalización del mundo contemporáneo ha afectado considerablemente a todos los sectores de la vida humana, incluyendo la ciencia, la tecnología y la educación. Aquí se destaca, principalmente, la educación escolar. Ésta, en el caso de Brasil, alcanzó cierta universalización, aunque su teleología central está más orientada hacia las demandas del mercado, en detrimento de la formación cultural y humana. A partir de estas consideraciones, este artículo objetiva disertar sobre algunas concepciones de Marcuse y de Adorno relacionadas a la teoría crítica. Esas reflexiones pueden contribuir al esclarecimiento acerca de la sociedad tecnológica y de la barbarie que en ella impera, como condicionantes de los complejos sociales, entre ellos la educación escolar. En ese sentido, la teoría crítica y, consecuentemente, el esclarecimiento podrán contribuir a la superación de esa dinámica social instrumental con vistas a una educación escolar emancipatoria.

Palabras-clave: Sociedad Tecnológica; Teoría Crítica; Esclarecimiento; Educación Emancipadora.

\section{Introdução}

A globalização do mundo contemporâneo significou também a globalização da ciência, da tecnologia e da educação. Aqui se insere principalmente a educação escolar, que, no caso do Brasil, atingiu certa universalização, embora a sua teleologia central esteja voltada para as demandas do mercado, e não para a formação cultural e humana. Isso nos conduz à necessidade de pensarmos sobre os condicionamentos sociais marcados pela sociedade tecnológica e pela lógica do mercado capitalista, que impõem mecanismos de formação na educação escolar para atender às suas demandas.

Leo Maar introduzindo a obra Educação e Emancipação, de Adorno, destaca que, já na década de 1960, este autor comenta acerca do deslumbramento geral em virtude da globalização e, em particular, o deslumbramento “[...] relativo à educação, que ameaça o conteúdo ético do processo formativo em função de sua determinação social" (LEO MAAR, 1995, p. 11). Trata-se do condicionamento social na ótica do mercado capitalista, dos conhecimentos técnicos e do lucro. Ainda parafraseando Adorno ele diz que "[...] quanto mais a educação procura se fechar ao seu condicionamento social, tanto mais ela se converte em mera presa da situação social existente" (LEO MAAR, 1995, p. 11). Nesse condicionamento, ocorrem as deficiências no processo da educação escolar, provocando a semiformação, a exclusão, o incremento do trabalho precário e mal pago, a intensificação da exploração e da competição. Todo esse cenário, ancorado na política neoliberal, encontra seu amparo na tríade ciência, técnica e educação, cuja função social se volta para a manutenção da confiança no 
mercado, o estímulo ao consumo e o favorecimento da competição globalizada, provocando, inclusive, a violência, a barbárie.

Diante disso faz-se mister que se compreendam as relações entre o poder econômico, político e cultural e a maneira pela qual as ideologias dominantes são constituídas e mediadas para a execução das políticas de educação escolar cuja teleologia se volta mais para a demanda do mercado globalizado do que para os imperativos da formação humana. Daí a necessidade do esclarecimento e do desenvolvimento de uma teoria crítica da sociedade industrial, tecnológica e capitalista para que se possa compreender essa dinâmica social instrumental e lutar para a sua superação.

Isso posto, esclarecemos que não é nossa pretensão discorrer sobre o processo da educação escolar, mas sim apontar, a partir de considerações sobre sociedade tecnológica e razão instrumental, elementos de uma teoria crítica tendo em vista a promoção do esclarecimento acerca das suas demandas e condicionamentos para que possa contribuir, como uma das mediações, para uma educação escolar emancipatória. Tomaremos como pressuposto as concepções de dois importantes representantes da escola de Frankfurt ${ }^{1}$ : Marcuse e Adorno. Acreditamos que a teoria desses pensadores nos oferece suportes embasadores que possibilitam o esclarecimento para uma reflexão crítica e elucidativa sobre a sociedade tecnológica e mercadológica que induz à competição e à barbárie, o que afeta principalmente a educação escolar que passa a ser instrumento do mecanismo dessa sociedade.

Baseados nesses pensadores, partimos do pressuposto de que, embora no momento atual predomine a estrutura socioeconômica da sociedade mercadológica, que gera um descontentamento generalizado em relação ao ser-digno-do-homem, é possível pensarmos sobre os seus condicionamentos e sobre as ideologias que aí imperam e, a partir dessa discussão, exercermos o esclarecimento e, com ele, buscarmos vias e estratégias que possam contribuir para a superação dessa estrutura social. No nosso caso, o esclarecimento poderá contribuir para a superação de uma política de educação voltada principalmente para atender as demandas do mercado globalizado e, consequentemente, a teoria crítica e o esclarecimento poderão ser uma das mediações para a aquisição de uma educação escolar emancipatória.

Sabemos que teoria crítica da Escola de Frankfurt, baseada no materialismo histórico, direciona-se para a análise da estrutura e superestrutura da sociedade tecnológica e capitalista, no sentido de pensar a dominação dos homens pelos homens que nela impera e ainda busca

\footnotetext{
${ }^{1}$ A Escola de Frankfurt foi criada na Alemanha em 1923 com o objetivo de instaurar uma teoria crítica da sociedade desenvolvida. Dentre os seus diversos representantes Marcuse e Adorno merecem destaque.
} 
verificar como essa sociedade reproduz seus poderes sobre os indivíduos e porque os próprios homens participam da sua desumanização. Como resgatar, então, a potencialidade transformadora dos homens? Como estabelecer uma teleologia, que se efetive na prática, no âmbito da política de uma educação escolar voltada para a formação ética, profissional e humana capaz de desenvolver realmente, na teoria e na prática, o ser digno do homem? Para a teoria crítica, o grande passo consiste no esclarecimento, na desvelação da estrutura capitalista que gerou uma sociedade tecnológica como instrumento de poder e transmutou a razão filosófica e humana em razão científica e instrumental. Eis a grande contribuição desses elementos da teoria crítica para o esclarecimento e, assim, elucidar a finalidade e as demandas de uma política de educação escolar voltada para os interesses do mercado.

Marcuse nos oferece fortes contribuições com a sua crítica à racionalidade dominadora e instrumental da sociedade industrial. Para ele, os ideais do iluminismo, de liberdade e racionalidade, fracassaram diante dessa sociedade industrial, cuja razão predominante é a razão instrumental, que domina e bloqueia o próprio homem. Diante dessa constatação, ele defende a necessidade de se desmistificar a alienação humana e de se reconhecer o mundo como um sistema reificado. E isso certamente remete ao esclarecimento.

Também Adorno admite que, na sociedade industrial, impera um irracionalismo. Diante dessa consideração, ele disserta sobre a significação da dominação e da barbárie nessa sociedade. Para ele, o homem tem que fazer uso do seu próprio entendimento, quer dizer, do esclarecimento, da sua própria razão. Fazer uso da razão é uma atitude eminentemente prática e política, e não especulativa. No entanto, a razão esclarecida, emancipatória, tornou-se instrumental, uma vez que foi reprimida com o desenvolvimento da sociedade tecnológica. Para Adorno, a afirmação da dimensão instrumental da razão é a negação da sua dimensão humana e emancipatória. Porém, é possível o seu resgate através de uma reflexão crítica e do esclarecimento. Essa reflexão representa um elemento fundamental na luta por uma educação emancipatória, pois, através dela, é possível perceber e superar a lógica da dominação que interfere em todos os setores sociais, inclusive na política e na prática da educação escolar.

É a partir desse referencial que Marcuse e Adorno postulam o papel ativo do homem na sua historicidade. Para eles, da mesma forma que o homem gerou sua situação social alienada, também pode gerar uma situação social emancipada, já que ele é o sujeito da sua própria história e, portanto, das suas relações sociais. Então, são eles próprios que elaboram e reelaboram as ideologias, finalidades e estratégias das suas práticas sociais e educacionais. 


\section{Crítica de Marcuse à Razão Instrumental Predominante na Sociedade Tecnológica}

Marcuse reconhece que o progresso técnico trouxe grandes benefícios para a humanidade de tal modo que poderia atender a todas as suas necessidades; no entanto o caráter instrumental desse progresso acabou por predominar na vida humana. É por esse viés que ele procura analisar como uma sociedade desumanizada, marcada por uma racionalidade tecnológica e instrumental, continua a manter o controle sobre os seus membros e como é possível que estes possam participar, tanto na vida cotidiana como nas suas políticas de sociabilidade, da produção da sua própria desumanização e exploração. Ao fazer essa análise, ele exerce uma forte crítica à sociedade tecnológica e à razão instrumental, tomando principalmente as concepções de Marx, ao considerar o homem como sujeito da sua história e, portanto, das mudanças sociais; e de Freud, ao considerar o principio de realidade como guia social das ações dos homens e que é resultante das próprias condições sócio-históricas.

$\mathrm{Na}$ sociedade tecnológica esse princípio de realidade, que se manifesta como princípio de desempenho - cuja maior expressão é o trabalho explorado, alienado - é guiado por uma ordem repressiva e alienante. Mas o próprio sistema atual gera as condições da sua superação, como afirma Marcuse (1981b, p. 28): “as próprias realizações da civilização repressiva parecem criar as precondições para a gradual abolição da repressão". Portanto, apesar do desenvolvimento tecnológico, que deveria proporcionar um bem-estar do ser humano, o que se verifica é o controle e o caráter repressivo desse desenvolvimento, que é voltado para a manutenção do poder existente na sociedade. Nesse sentido, os ideais do iluminismo (liberdade e racionalidade), cuja promessa era salvar o homem do fanatismo, do desconhecimento, da falta de esclarecimento e do medo, resultaram em fracasso. No entanto, é no seio dessa mesma sociedade que se geram as condições para a abolição da repressão, o que certamente remete a uma educação emancipatória

Em seu livro A ideologia da sociedade industrial (1979), Marcuse considera que os ideais de liberdade defendidos pela ideologia burguesa não conseguiram realizar a sua suposta missão de emancipação humana. Pelo contrário, o homem, na sua tentativa de domínio absoluto sobre a natureza, termina por desenvolver um domínio sobre os outros homens e sobre si próprio. A razão, como resultado desse processo, perde a sua potencialidade crítica, passando a ser instrumental e, paradoxalmente, irracional ${ }^{2}$.

\footnotetext{
${ }^{2}$ Marcuse considera que o racionalismo da sociedade industrial provoca a destruição crescente e alienante dos seus membros; portanto, “[...] o seu racionalismo arrasador, que impele a eficiência e o crescimento, é, em si, irracional” (MARCUSE, 1979, p. 17).
} 
Embora se afirme como liberal e democrática, a sociedade industrial é que produziu esse fruto. Tal democracia, assim como o desenvolvimento do potencial humano, reduz-se ao consumismo e ao mercado. Nesse sentido,

[...] as criaturas se reconhecem em suas mercadorias; encontram sua alma em seu automóvel, hi-fi, casa em patamares, utensílios de cozinha. O próprio mecanismo que ata o indivíduo à sua sociedade mudou, e o controle social está ancorado nas novas necessidades que ela produziu [...]. No período contemporâneo, os controles tecnológicos parece serem a própria personificação da Razão para o bem de todos os grupos e interesses sociais a tal ponto que toda contradição parece irracional e toda ação contrária parece impossível. (MARCUSE, 1979, p. 29. O grifo é do autor).

Vale salientar que a crítica de Marcuse à sociedade industrial não se reduz a uma crítica puramente negativa, como se a técnica não trouxesse benefícios ao homem; porém, trata-se de mostrar as consequências de uma sociedade baseada única e exclusivamente na ciência experimental. Segundo ele, a característica fundamental da nossa sociedade é a técnica, o que dificulta a aquisição de uma atitude crítica diante das ações e dos valores humanos fetichizados, resultando numa sociedade sem oposição, decorrendo uma paralisia da crítica.

É a partir dessas colocações que o nosso autor volta-se para uma análise da estrutura social capitalista, principalmente dos países altamente industrializados; fala ainda sobre o grande paradoxo: ao mesmo tempo em que a sociedade se torna cada vez mais rica, maior é o perigo de uma guerra atômica. Nesse sentido, as causas da dominação não são identificadas, posto que os esforços para impedir a catástrofe dessa guerra "[...] ofuscam a procura de suas causas potenciais na sociedade industrial contemporânea” (MARCUSE, 1979, p.13). Porém, não é difícil identificar que "[...] a exploração e a repressão pertencem à essência da produção capitalista, como também a guerra e a concentração do poder científico pertencem à essência da produção capitalista” (MARCUSE, 1974, p. 28). Por esse raciocínio, é possível afirmar que também todos os complexos sociais, incluindo as políticas de educação escolar e as suas práticas, pertencem a essa essência da produção capitalista.

Por conseguinte, a investigação das raízes da irracionalidade presente na sociedade industrial e o exame de suas alternativas históricas “[...] são parte do objetivo de uma teoria crítica da sociedade contemporânea" (MARCUSE, 1979, p. 14, grifo nosso). A teoria crítica revela a alienação humana da sociedade industrial, reconhece o mundo como um sistema reificado e acredita que a estrutura dessa sociedade pode ser rompida. Diz Marcuse (1979, p. 
222): “Acentuei repetidamente o caráter histórico das necessidades humanas; [...] numa sociedade livre e racional serão diferentes das produzidas numa irracional e não livre”.

A construção dessa sociedade livre pressupõe uma ruptura com a atual sensibilidade mutilada. Aqui Marcuse lembra a tese de Marx sobre a dimensão social dos sentidos humanos e destaca que a emancipação dos sentidos implica a sua praticidade:

A emancipação dos sentidos implica que os sentidos tornam-se práticos na reconstrução da sociedade, que eles geram novas relações [...] entre homem e homem, homem e coisas, homem e natureza. Mas os sentidos tornam-se também fontes de uma nova racionalidade [...] liberta da racionalidade da exploração. (MARCUSE, 1981a, p. 67-68, grifo do autor).

Marcuse está se referindo a uma educação emancipatória, isto é, a uma educação dos sentidos e afirma que, numa sociedade “[...] baseada no trabalho alienado, a sensibilidade humana está embotada: os homens só percebem as coisas nas formas e funções em que lhes são dadas, feitas, usadas pela sociedade existente" (MARCUSE, 1981a, p. 74, grifo do autor). Podemos dizer também que, em relação às políticas e às práticas da educação escolar, elas só são percebidas nas “formas e funções em que lhes são dadas". Desse modo, a sociedade atual, com todos os seus complexos, é reproduzida não apenas na mente dos homens, mas também nos seus sentidos. Segundo Marcuse, o agente revolucionário para um novo tipo de sociedade, que compreenda o pensamento crítico e uma nova educação dos sentidos, "[...] gera-se na práxis, surge no desenvolvimento da consciência, no processo de ação” (MARCUSE, 1974, p. 25).

A razão filosófica, em contraposição a uma razão instrumental, e por meio de uma teoria crítica, tem um importante papel no desenvolvimento da consciência esclarecida, porquanto se caracteriza como uma atitude crítica da realidade, sendo mentora da investigação intelectual e da essência dos fatos. É esse, segundo Marcuse, o compromisso histórico da filosofia. Entretanto, a filosofia contemporânea "[...] raramente conseguiu uma formulação mais estética do conflito entre seu intento e sua função" (MARCUSE, 1979, p. 202). Isso porque a dimensão crítica da filosofia se perdeu em detrimento das ciências positivas. Para estas só importam os fatos e não a verdade, a liberdade e o sentido das coisas; dimensões estas que fizeram parte da filosofia tradicional e se perderam na contemporaneidade. Daí porque a filosofia contemporânea não é crítica; todavia, é possível a sua recuperação pelos homens ao sair da razão instrumental e voltar para a razão filosófica, para o esclarecimento. 


\section{Considerações de Adorno Acerca da Fetichização da Técnica e da Barbárie Humana}

Assim como Marcuse, Adorno também admite a crise da razão na sociedade contemporânea na medida em que ela se transformou, paradoxalmente, em razão "irracional". Destaca-se aqui a razão instrumental que se tornou onipresente com o desenvolvimento do capitalismo. Ela está voltada para a sociedade tecnológica e serve como ferramenta de dominação e de exploração do trabalho. Seu objetivo maior dirige-se para a ampliação do capital, resultando na barbárie a que chegou a humanidade.

Adorno admite a superação dessa barbárie, inclusive por meio do esclarecimento, mas constata a dificuldade de tal superação no quadro do capitalismo tardio, diz ele: "Progresso e barbárie estão hoje [...] tão enredados que só uma ascese bárbara contra essa última e contra o progresso dos meios seria capaz de produzir de novo a não barbárie" (ADORNO, 1992, p. 43). Apesar de tais dificuldades, ele não perde a esperança de encontrar saídas para a atual situação. E aposta muito numa educação emancipatória. Nesse sentido afirma (1995): “a exigência que Auschwitz não se repita é a primeira de todas para a educação" (p. 119). Não obstante, predomina ainda os limites proporcionados pela razão instrumental.

Diante desses limites, ele busca uma compreensão do fator subjetivo, destacando o que denomina a volta do sujeito. Aqui ganha relevo a questão da educação, da psicanálise e da autorreflexão, pois a atomização do trabalho na sociedade tecnológica corresponde à atomização do indivíduo. Essa sociedade, cuja racionalidade está fundada no valor de troca, integra os indivíduos pelo sofrimento, resultando no seu estranhamento, no seu desenraizamento, na perda de referências, enfim, na sua falta de identidade. Para Adorno, essa mudança na psicologia do indivíduo possibilitou Auschwitz ${ }^{3}$. É preciso, pois, recuperar a integridade, mas, um indivíduo de caráter íntegro só poderia ser possível numa sociedade íntegra. Portanto,

[...] a deformação não é nenhuma doença no homem, e sim uma doença da sociedade, que gera suas crias [...] A consumação da divisão do trabalho no indivíduo, sua objetivação radical, conduz à sua cisão doentia. Daí o caráter psicótico, o pressuposto antropológico de todos os movimentos de massa totalitários. (ADORNO, 1992, p. 201-202).

\footnotetext{
${ }^{3}$ Auschwitz foi um dos maiores campos de concentração nazistas. No seu livro Educação e emancipação (1995), Adorno dedica-lhe uma parte, denominada Educação após Auschwitz, cuja ideia inicial coloca a educação como o centro para o impedimento de uma nova barbárie.
} 
Adorno (1992) considera que a razão instrumental e a fetichização da técnica, presentes na sociedade contemporânea, são criadoras de esquizofrenia, incidindo sobre a psicologia dos indivíduos, tornando as pessoas incapazes de amar. No entanto, esse fato não deve ser entendido num sentido sentimental ou moralizante. Trata-se de revelar que a capacidade de amar é absorvida por coisas: máquinas, objetos, etc.

Existe uma grande deficiência hoje das pessoas com relação ao amor, por conta da nova ordem social. Daí porque é difícil mobilizá-las para o calor humano quando são produtos de uma sociedade cujas marcas ostentam. Da mesma forma, é difícil exigir amor nas relações profissionais intermediadas entre professor e aluno, médico e paciente, advogado e cliente, etc. Diz Adorno (1995, p. 135-136):

O incentivo ao amor - provavelmente na forma mais imperativa, de um dever - constitui, ele próprio, parte de uma ideologia que perpetua a frieza. Ele combina com o que é impositivo, opressor, que atua contrariamente à capacidade de amar. Por isso o primeiro passo seria ajudar a frieza a adquirir consciência de si própria, das razões pelas quais foi gerada.

Essa falta de amor levou à ocorrência do nazismo. Se os homens não fossem indiferentes ao que sucede aos outros, Auschwitz não teria acontecido. Esse fato é uma característica típica da barbárie. Por conseguinte, "a tentativa de superar a barbárie é decisiva para a sobrevivência da humanidade" (ADORNO, 1995, p. 156). Entretanto, a forma como a barbárie se reveste nos dias de hoje em nome de autoridades e de poderes estabelecidos leva ao impulso destrutivo e à essência mutilada da maioria das pessoas. Para o nosso autor, a barbárie existe onde há violência física, genocídio, racismo, tortura, repressão, guerras, etc. Tais elementos são revestidos por uma suposta democracia, liberdade e cidadania, pretensamente praticadas pelos detentores do poder.

Tudo isso resulta também no empobrecimento cultural e, consequentemente, no empobrecimento também das políticas de ação da educação escolar, que carregam, em sua estrutura, a marca da fetichização da técnica e da cultura. Portanto, na sociedade fetichizada, manifesta-se a indústria cultural, pois a cultura no capitalismo tornou-se uma semicultura ao exercer uma função de legitimação e dominação, deixando embotar a sua dimensão formativa.

Os bens da indústria cultural produzem, de imediato, satisfação aos nossos desejos, porém não se deve esquecer que ela tem uma base objetiva, sendo esta também uma das causas da barbárie capitalista. Nesse sentido, a indústria cultural tanto incide nos fatores subjetivos - quando, por exemplo, por intermédio da cultura as pessoas experimentam 
fracassos, desenvolvendo sentimentos de culpa que acabam em agressão - como nos fatores objetivos. Adorno cita como uma razão objetiva a falência da própria cultura:

A cultura, que conforme sua própria natureza promete tantas coisas, não cumpriu sua promessa. Ela dividiu os homens. A divisão mais importante é aquela entre trabalho físico e intelectual. Deste modo ela subtraiu aos homens a confiança em si e na própria cultura. (ADORNO, 1995, p. 164).

É preciso perceber que a mercantilização da cultura, isto é, a indústria cultural impede a atuação de uma racionalidade livre, do esclarecimento e da liberdade, enfim, de uma educação emancipatória. No entanto, toda situação de barbárie, resultante da sociedade tecnológica, requer a sua própria superação ${ }^{4}$. Faz-se necessário, então, a substituição da razão instrumental pela recuperação da razão filosófica, para elucidar essas mazelas da sociedade capitalista e tecnológica, o que requer o estabelecimento de uma teoria crítica e do esclarecimento. Essa nova razão liberta o homem do jugo da repressão, da ignorância e da inconsciência.

Adorno considera que a educação enquanto processo de formação tem um grande peso nessa tarefa. E aqui podemos remeter à educação escolar, tanto em relação a sua política educacional mais ampla, como também em relação às ideologias, finalidades e ações nas suas diversas instituições como: escolas e universidades. A educação, aí compreendida, deveria proporcionar a formação de indivíduos autônomos, independentes e esclarecidos capazes de entender a sua situação sócio-histórica, de julgar e de tomar decisões de forma consciente. Em consequência, a educação deveria contribuir também para a superação e impedimento de uma nova barbárie, tornando-se emancipatória. Falando da necessidade dessa superação, Adorno afirma: “[...] considero tão urgente impedir isto que eu reordenaria todos os outros objetivos educacionais para esta prioridade" (ADORNO, 1995, p. 155).

No entanto, na sociedade tecnológica e capitalista percebe-se a ausência de uma educação escolar realmente formadora. A finalidade e os objetivos das políticas educacionais que nela imperam têm, em tese, boas intenções, mas, na prática, não são, de fato, voltadas para a ideia de emancipação. Nesse sentido Adorno (1995, p. 169) afirma que só se pode caminhar para a emancipação "por meio do esclarecimento", portanto, "emancipação significa o mesmo que conscientização, racionalidade" (idem, p. 143). A educação escolar tem um grande peso nessa tarefa.

\footnotetext{
${ }^{4}$ É nesse ponto que consiste a crítica negativa de Marcuse e de Adorno. A sua intenção volta-se para a negação da exploração do trabalhador e da barbárie presentes no capitalismo, cujo ponto norteador é a transformação da razão instrumental em razão emancipatória. Isso pode ocorrer porque o homem tem a potencialidade de conscientização e de esclarecimento da sua própria situação.
} 


\section{Para concluir}

Nas últimas décadas, com o estabelecimento da globalização, as demandas pela formação do homem por meio da educação escolar têm se intensificado consideravelmente. No Brasil, a política de expansão da educação escolar, principalmente em relação à educação básica, tem a sua teleologia voltada para a democratização do ensino expressa em vários documentos governamentais. No entanto, ainda há uma carência nesse nível de formação tanto em termos de quantidade e, mais ainda, em termos de qualidade. No primeiro caso - a questão da quantidade -, há uma carência nas escolas públicas, pois estas ainda não foram expandidas o suficiente para o atendimento da população. No segundo caso - a questão da qualidade -, há uma carência tanto nas escolas particulares, que na sua grande maioria tem o caráter mercadológico ao conceber o aluno como uma mercadoria; como também e principalmente nas escolas públicas que, apesar da sua expansão - porém ainda a desejar -, carece também de condições objetivas materiais e humanas, nesse último caso, por não haver uma valorização do professor e também as condições necessárias para a sua prática docente capaz de proporcionar uma formação humana e emancipatória aos seus alunos. Desse modo, as teleologias e as ações das políticas de educação escolar se pavimentam nas demandas: ora dos fins lucrativos, ora da formação da mão-de-obra barata. Em ambos os casos a direção, em última instancia, são os interesses do mercado capitalista.

Isso é fruto de uma sociedade cientificizada e competitiva que leva à heteronomia dos homens. Vimos que as concepções de Marcuse e de Adorno retratam bem essa situação: a sociedade tecnológica e capitalista transforma a razão filosófica em razão científica, instrumental, levando os homens à alienação e à barbárie. Tudo isso interfere nos complexos sociais, dentre eles, a educação escolar, que terminam por satisfazer o caráter competitivo da economia global.

Em que pesem os impasses mais significativos dessa sociedade, Marcuse e Adorno acreditam no poder transformador, de conscientização e de esclarecimento dos próprios homens, o que remete a uma educação emancipatória.

Marcuse não aponta diretamente as vias para a formação dessa consciência esclarecida, entretanto nos fornece uma ampla reflexão acerca da sociedade industrial e da alienação que nela impera. Portanto, embora possa parecer ambíguo, a sociedade industrial mesmo sendo unidimensional e tendo como direção a competição e o lucro - 
contraditoriamente, abre espaço para novas formas de contestação da ordem instituída, pois a revolução não nasce primariamente da pobreza, mas sim da desumanização global. Porém, adverte Marcuse, a teoria crítica não pode ser meramente especulativa, ela é focalizada na união “[...] da teoria e da prática, do pensamento e da ação no processo teórico” (MARCUSE, 1979, p. 126).

Essas posições teórico-metodológicas são intensificadas e ampliadas por Adorno. Para ele, a educação tem um papel fundamental nesse processo de conscientização e de esclarecimento. Não se trata de atribuir à educação o poder de resolver o problema da barbárie capitalista, porém a sua contribuição para isso é bastante significativa, uma vez que não se realiza qualquer luta sem o conhecimento e a reflexão que a envolve. A educação formal em si não reduz as desigualdades, mas a educação crítica pode fornecer fortes elementos para a formação de um homem crítico, capaz de pensar a sua vida social e de saber como agir para transformar a atual realidade, que tem como cenário a barbárie capitalista.

Diante das colocações aqui expostas, reafirmamos que Marcuse e Adorno acreditam na possibilidade de compreensão e de transformação do mundo social, tendo em vista uma educação emancipatória, cujo requisito primeiro é o esclarecimento por meio de uma teoria crítica. No caso de Marcuse, embora não tenha dedicado uma obra de forma sistemática sobre essa posição, ele afirma, em um dos seus vários escritos, que "[...] a evolução da consciência, do pensamento crítico, constitui uma tarefa decisiva das universidades e das escolas" (MARCUSE, 1974, p. 26). Destaca-se aqui a necessidade de uma grande atenção acerca da educação escolar cuja formação tem uma responsabilidade ímpar para essa direção. É assim que se torna necessário e possível o estabelecimento de novas finalidades e ações no âmbito da educação escolar posto que ela também tem as potencialidades para ser agente de transformação e emancipação. Não acreditar nessa possibilidade é cair no pessimismo e no descrédito. Marcuse e Adorno nos fornecem elementos para elucidar que as políticas da educação escolar no capitalismo estão voltadas para os interesses dominantes, mas também nos fazem refletir acerca do seu papel histórico, transformador e emancipatório e que tem, como requisito primeiro, o esclarecimento.

\section{REFERENCIAS}

ADORNO, Theodor. Educação e emancipação: entrevistas e ensaios. Tradução de Wolfgang Leo Maar. São Paulo: Paz e Terra, 1995. 
ADORNO, Theodor. Minima moralia. Tradução de Luis Eduardo Bicea. São Paulo: Ática, 1992.

ADORNO, Theodor. Tabus a respeito do professor. In: ZUIN, Antonio Álvaro Soares et al. Adorno: o poder educativo do pensamento crítico. Petrópolis: Vozes, 1999. p. 157-184.

LEO MAAR, Wolfgang. À guisa de introdução: Adorno e a experiência formativa. In: ADORNO, Theodor. Educação e emancipação: entrevistas e ensaios. Tradução de Wolfgang Leo Maar. São Paulo: Paz e Terra, 1995. p. 11- 28.

MARCUSE, Herbert. A ideologia da sociedade industrial. Tradução de Giasone Rebuá. 5. ed. Rio de Janeiro: Zahar, 1979.

MARCUSE, Herbert. Contrarrevolução e revolta. Tradução de Álvaro Cabral. 2. ed. Rio de Janeiro: Zahar, 1981a.

MARCUSE, Herbert. Eros e civilização. Tradução de Álvaro Cabral. 8. ed. Rio de Janeiro: Zahar, 1981b.

MARCUSE, Herbert; POPPER, Karl. Revolução ou reforma?: uma confrontação. Lisboa: Morais Editores, 1974.

\section{SOBRE OS AUTORES:}

\section{Fátima Maria Nobre Lopes}

Doutora em Educação pela Universidade Federal do Ceará (UFC). Professora da UFC. Docente do Curso de Pedagogia e do Programa de Pós-Graduação em Educação da UFC. Líder do Grupo de Pesquisa Ontologia do Ser Social, Ética e Formação Humana (GEPOS). Email: fatimanobreufc@gmail.com

\section{Adauto Lopes da Silva Filho}

Doutor em Educação pela Universidade Federal do Ceará (UFC). Professor da UFC. Docente do Curso de Filosofia, do Programa de Pós-Graduação em Filosofia e do Programa de PósGraduação em Educação da UFC. Líder do Grupo de Pesquisa Filosofia, Teoria Crítica e Educação. E-mail: adautoufcfilosofia@gmail.com 